\title{
Easy on the mind, easy on the wallet: The roles of familiarity and processing fluency in valuation judgments
}

\author{
Adam L. Alter And Daniel M. Oppenheimer \\ Princeton University, Princeton, New Jersey
}

\begin{abstract}
Although people routinely estimate the value of items in their environment, from goods and services to natural resources and lost earnings following an accident, the processes that underlie human valuation estimates are not well understood. We show that people use familiarity and fluency - the ease with which they process information - to determine an item's value. In three experiments, participants believed that familiar forms of currency (e.g., a familiar \$1 bill) had greater purchasing power than their unfamiliar counterparts (e.g., a rare and unfamiliar coin). Mechanistic analyses showed a positive correlation between participants' familiarity with the unfamiliar currency and their estimates of its value. We conclude by discussing the theoretical and practical implications of our findings for researchers, marketing experts, and policymakers alike.
\end{abstract}

Valuation estimates govern both routine decisions, such as whether to buy and sell goods and services, and larger decisions, such as whether to attend college and which vocation to pursue. Although valuation is a fundamental component of human judgment, our understanding of the principles that determine how people actually appraise a target's value is incomplete.

Financial and economic models explain the steps involved in monetary valuation, but many assume that human valuers are consistently rational. For example, the efficient market hypothesis (Fama, 1965) assumes that investors reevaluate market prices instantly and rationally when exposed to new information; thus, a single investor cannot systematically outperform the market in the short term. This definition assumes that informed investors are perfectly rational agents, immune from subjective or suboptimal behavior.

In fact, many human valuation judgments tend to be biased (Tversky \& Kahneman, 1974). The endowment effect is one particularly well-cited example, according to which people perceive greater value in goods that they wish to sell than in identical goods they are attempting to buy (Thaler, 1980). Other researchers have also shown that sellers, buyers, and disinterested third parties adopt very different approaches to valuation tasks because they weight the same information quite differently (e.g., Birnbaum \& Zimmermann, 1998).

Like buyers and sellers, people who interact with newly introduced or foreign currency exhibit a series of systematic valuation biases. For example, despite understanding the relevance of exchange rates, travelers tend to spend according to the face value of foreign currencies rather than their value in real terms (Raghubir \& Srivastava, 2002).
The introduction of the euro in 2002 and the deletion of six zeroes from the Turkish lira in 2005 created similar valuation anomalies among Europeans across several countries (Cannon \& Cipriani, 2006).

Other researchers have considered a range of specific valuation biases (for a review, see Raghubir, 2006). For example, people are more reluctant to spend a $\$ 100$ bill than to spend an equal amount with a gift certificate purchase (Raghubir \& Srivastava, in press), a credit card purchase (Prelec \& Simester, 2001), or successive purchases using smaller denominations that sum to $\$ 100$ (Mishra, Mishra, \& Nayakankuppam, 2006). These studies suggest that people struggle to objectively valuate currency and consumables in the face of numerous cognitive biases.

Many attempts at valuation are similarly plagued by the subjectivity produced by valuation contexts. For example, judges and juries attempt to translate a plaintiff's pain into the language of monetary value when assigning damages in a negligence suit (Sunstein, Hastie, Payne, Schkade, \& Viscusi, 2002). Likewise, national governments periodically weigh the costs of deforestation against the benefits of a new highway, or they question whether the threat of global warming warrants costly power plant upgrades (Hanemann, 1994).

Such subjective judgments are laced with uncertainty, and humans tend to respond to uncertainty by adopting a variety of judgmental heuristics (see, e.g., Tversky \& Kahneman, 1974). These heuristics, or cognitive shortcuts, simplify the valuation process, but they also introduce a range of suboptimal cognitive biases. For example, the U.S. government spends millions of dollars filtering arsenic from drinking water, while ignoring other hazards that appear less harm-

A. L. Alter, aalter@princeton.edu 
ful but actually kill many more people (Sunstein, 2002). Governments regularly allocate resources according to how much fear a toxin engenders, rather than according to how many people it affects in reality, which often results in the dramatic misallocation of funds (Slovic, 2000).

\section{Familiarity and Valuation}

According to the mere exposure effect (Zajonc, 1968), familiar items are preferred to their unfamiliar, but otherwise identical, counterparts. Since familiarity generates the experience of liking, one might expect a familiar and therefore more likable item to also seem more valuable. One explanation for this effect is that familiar items become increasingly appealing because they become more fluently or easily processed (see, e.g., Fang, Singh, \& Ahluwalia, 2007). Indeed, using items of varying degrees of familiarity is one of many techniques that researchers have used to manipulate processing fluency (e.g., Alter \& Oppenheimer, 2008a, 2008b; Alter, Oppenheimer, Epley, \& Eyre, 2007).

Although few studies have directly considered the role of familiarity in valuation processes, one recent article examined whether the ease or fluency of pronouncing a stock's name influenced its performance immediately following its initial public offering (Alter \& Oppenheimer, 2006). Stock performance data from the New York and American Stock Exchanges between 1990 and 2004 showed that fluently named stocks outperformed disfluently named stocks. Arguing for a similar mechanism, Mishra et al. (2006) noted that people are more reluctant to spend notes of larger denominations (e.g., a $\$ 50$ bill) than to use several smaller notes with an equivalent value (e.g., five $\$ 10$ bills), in part because a $\$ 50$ bill is more easily quantified.

For the present article, we examined the relationship between familiarity and valuation directly and sought to show that unfamiliar forms of currency seem less valuable than their more familiar, but otherwise identical, counterparts (Experiments 1-3). We manipulated the familiarity of the currency in our experiments by presenting either more common or less common forms of currency in Experiments 1 and 2, and either real or subtly altered versions of real currency in Experiment 3.

We expected that familiarity might influence valuation judgments through different routes. Unfamiliar vi- sual stimuli tend to be more difficult to process visually (e.g.,Winkielman \& Cacioppo, 2001), and less familiar stimuli are more difficult to remember (e.g., Tversky \& Kahneman, 1973). Both perceptual difficulty and unfamiliarity are forms of processing disfluency that tend to engender disliking. Moreover, participants may more readily recall using the familiar forms of currency, thereby associating them with greater value than that of their unfamiliar counterparts. Regardless of which cognitive route engendered disfluency, we expected that unfamiliar currency instruments would seem less valuable than their more familiar counterparts.

\section{EXPERIMENT 1}

\section{Method}

Participants. Thirty-seven university staff and graduate students were recruited from a dining hall at Princeton University.

Design, Materials, and Procedure. Participants completed a one-page questionnaire in which they estimated how many of each of 10 inexpensive items they could purchase with $\$ 1$ (items listed in Table 1).

Participants completed either a familiar-currency version or an unfamiliar-currency version of the questionnaire. The familiarcurrency questionnaire contained a picture of a standard $\$ 1$ bill, whereas the unfamiliar-currency questionnaire contained a picture of a Susan B. Anthony $\$ 1$ coin (forms of currency from Experiments 1-3 are depicted in Figure 1). Produced in limited quantities from 1979 to 1981 and in 1999, Susan B. Anthony coins are considerably rarer than $\$ 1$ bills, which constitute $45 \%$ of all notes produced by the Bureau of Engraving and Printing (Bureau of Engraving and Printing, 2008). Accordingly, although both forms of currency are equally valuable, we expected that participants would be more familiar with the $\$ 1$ bill and therefore would value the $\$ 1$ bill more highly.

At the end of the questionnaire, participants reported their familiarity with the form of currency depicted at the top of the page, using a scale ranging from 1 (never seen before) to 7 (seen more than 50 times).

\section{Results and Discussion}

Manipulation check. As we expected, participants were significantly more familiar with the $\$ 1$ bill $(M=$ $7.00, S D=0.00)$ than they were with the $\$ 1$ Susan B. Anthony coin $(M=4.18, S D=2.24)[t(35)=5.13, p<$ $\left..001, \eta_{\mathrm{p}}^{2}=.43\right]$.

Table 1

Mean Perceived Purchasing Power of Currency (Expressed in Quantity Purchasable per Dollar) in Each Condition Across Experiments 1-3

\begin{tabular}{|c|c|c|c|c|c|c|c|}
\hline & \multicolumn{2}{|c|}{ Experiment 1} & \multicolumn{2}{|c|}{ Experiment 2} & \multicolumn{3}{|c|}{ Experiment 3} \\
\hline & $\begin{array}{l}\text { Familiar } \\
\text { Currency } \\
(\$ 1 \text { bill })\end{array}$ & $\begin{array}{c}\text { Unfamiliar } \\
\text { Currency } \\
\text { (rare } \$ 1 \text { coin) }\end{array}$ & $\begin{array}{c}\text { Familiar } \\
\text { Currency } \\
\text { (two } \$ 1 \text { bills) }\end{array}$ & $\begin{array}{c}\text { Unfamiliar } \\
\text { Currency } \\
\text { (rare } \$ 2 \text { bill) }\end{array}$ & $\begin{array}{c}\text { Disfluent } \\
\text { Items } \\
\text { (real \$1 bill) }\end{array}$ & $\begin{array}{c}\text { Familiar } \\
\text { Currency } \\
\text { (real } \$ 1 \text { bill) }\end{array}$ & $\begin{array}{c}\text { Unfamiliar } \\
\text { Currency } \\
\text { (altered } \$ 1 \text { bill) }\end{array}$ \\
\hline Gumballs & 9.53 & 6.70 & 12.67 & 10.71 & 3.82 & 6.17 & 5.09 \\
\hline Paper clips & 70.67 & 62.70 & 130.63 & 34.57 & 88.89 & 47.50 & 20.09 \\
\hline Wrapping paper (sq ft) & 9.88 & 11.07 & 26.88 & 8.57 & 11.21 & 3.33 & 1.81 \\
\hline Mexican pesos & 10.75 & 12.86 & 70.50 & 10.33 & 31.26 & 39.90 & 5.62 \\
\hline Pencils & 7.73 & 7.67 & 15.67 & 7.29 & 8.56 & 7.25 & 3.36 \\
\hline Pieces of Skittles candy & 57.08 & 40.68 & 66.67 & 29.00 & 34.22 & 13.60 & 11.67 \\
\hline Thumbtacks & 47.08 & 34.57 & 50.38 & 32.20 & 33.72 & 25.83 & 13.00 \\
\hline Sheets of $8.5 \times 11$ in. paper & 58.00 & 55.33 & 129.94 & 76.57 & 39.94 & 28.33 & 27.45 \\
\hline Hershey's Kisses & 21.27 & 14.19 & 32.67 & 25.86 & 18.22 & 9.81 & 9.10 \\
\hline White paper napkins & 70.36 & 56.85 & 102.88 & 71.67 & 58.94 & 38.82 & 22.10 \\
\hline
\end{tabular}




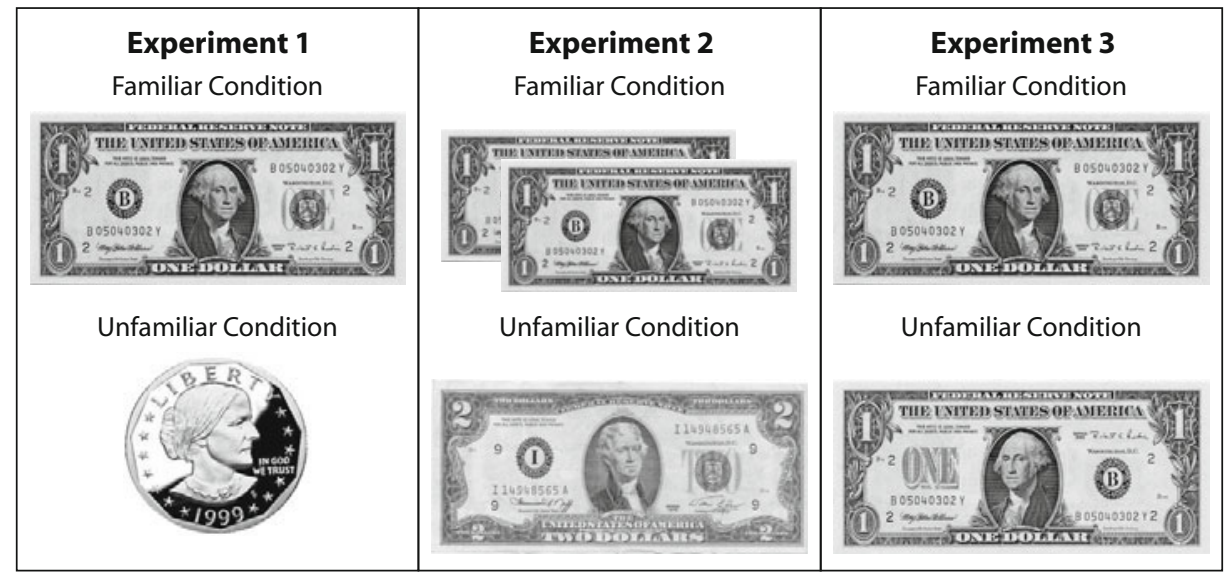

Figure 1. Familiar and unfamiliar forms of currency used in Experiments 1-3.

Primary analyses. We began by converting participants' purchasing power estimates to standardized $z$ scores, a process that we also adopted in Experiments 2 and 3. This allowed us to compare the estimates of the relatively more expensive and less expensive items on a single scale. For example, participants believed that they could purchase approximately eight pencils with $\$ 1$, whereas they believed they could purchase 64 paper napkins with the same $\$ 1$.

As we predicted, participants in the familiar-currency condition believed that they could purchase more of each item, on average, with $\$ 1$ than did participants in the unfamiliar-currency condition $[t(9)=2.24, p=.015$, $\left.\eta_{\mathrm{p}}^{2}=.54\right]$. (Figure 2 contains a graphical depiction of the results, pooled across experiments, and Table 1 contains the itemwise means from each experiment.) In support of a familiarity mechanism, furthermore, the more familiar the participants in the unfamiliar-currency condition were with the Susan B. Anthony coin, the greater their estimates of its purchasing power $[r(19)=.43, p<.05]$. Thus, participants believed that the monetary sum of $\$ 1$ had greater purchasing power when it was depicted in a familiar format. ${ }^{1}$

Experiment 1 provided preliminary evidence that unfamiliar forms of currency seem less valuable than their more familiar counterparts. An alternative explanation, however, is that coins seem inherently less valuable than bills, regardless of their relative familiarity (see, e.g., Mishra et al., 2006). This account cannot explain why participants who were more familiar with the Susan B. Anthony dollar valued it more highly. Even when we confined our analysis to participants in the coin condition, familiarity reliably influenced valuation judgments. Nonetheless, in Experiment 2 we addressed this concern by avoiding coins altogether. Instead, we presented participants in the familiar-currency condition with two regular $\$ 1$ bills, and we presented those in the unfamiliar-currency condition with one $\$ 2$ bill, a comparatively rarer note.

\section{EXPERIMENT 2}

\author{
Method \\ Participants. The experimenter recruited 39 adult volunteers at \\ a Princeton University campus dining hall.
}

Design, Materials, and Procedure. The questionnaire in this experiment was similar to the questionnaire used in Experiment 1, with several exceptions. First, participants estimated the quantity of each item that they could purchase with $\$ 2$. Second, the familiar-currency questionnaire depicted two $\$ 1$ bills, whereas the unfamiliar-currency questionnaire depicted one $\$ 2$ bill. Since there are 1,520 \$1 bills for every $\$ 2$ bill in circulation (Bureau of Engraving and Printing, 2008), we expected that participants would be more familiar with the $\$ 1$ bill than with the $\$ 2$ bill. At the end of the questionnaire, participants indicated their familiarity with the pictured form of currency on a 7-point scale.

\section{Results and Discussion}

Manipulation check. As we expected, participants were more familiar with the $\$ 1$ bill $(M=6.90, S D=0.31)$ than with the $\$ 2$ bill $(M=3.21, S D=2.04)[t(37)=7.99$, $\left.p<.001, \eta_{\mathrm{p}}^{2}=.63\right]$.

Primary analyses. Participants in the familiar-currency condition believed that they could purchase more of each item, on average, with $\$ 2$ than did participants in the unfamiliar-currency condition $\left[t(9)=4.23, p=.002, \eta_{\mathrm{p}}^{2}=\right.$ .67] (see Table 1 and Figure 2). Further supporting the proposed familiarity mechanism, participants in the unfamiliarcurrency condition who were more familiar with the $\$ 2$ bill believed that it had greater purchasing power than did those who were less familiar with it $[r(17)=.54, p=.02]$. Experiment 2 therefore replicated the results of Experiment 1, showing that participants perceived a more familiar form of currency to have greater purchasing power than that of its relatively unfamiliar counterpart.

In Experiment 3, we addressed two remaining concerns. First, participants in the familiar-currency condition may have perceived greater purchasing power merely because there were two bills in that condition and only one bill in the unfamiliar-currency condition. This alternative explanation contradicts previous research, however, which suggests that people perceive greater value in a single bill than in several lesser bills that add up to an equal monetary value (Mishra et al., 2006). ${ }^{2}$ Moreover, this alternative interpretation cannot explain why participants in the $\$ 2$ bill condition who were more familiar with the $\$ 2$ bill estimated it to have greater purchasing power than did participants who were less familiar. 




Figure 2. Mean purchasing power estimates across the familiar-currency and unfamiliar-currency conditions, collapsed across Experiments 1-3.

Nonetheless, in order to eliminate this concern in Experiment 3 , all participants completed a questionnaire depicting a single bill. We contrasted a real $\$ 1$ bill in the familiar-currency condition with a subtly altered $\$ 1$ bill in the unfamiliar-currency condition. The subtle alterations made the unfamiliar bill more difficult to process and, consequently, less familiar but did not affect its format, quantity, and face value. We expected to produce results similar to those from Experiments 1 and 2, in which participants perceived greater value in the familiar currency than in the unfamiliar currency.

Additionally, Experiments 1 and 2 showed that unfamiliar and therefore more disfluently processed currency instruments are undervalued, but any disfluently processed stimulus should seem less valuable than its more easily processed counterparts. Accordingly, in Experiment 3, we included a disfluent-items condition in which we left the currency unchanged but decreased the fluency of the purchasable goods. Since unfamiliar and therefore disfluent currency instruments seem to be valued less highly, we assumed that disfluent consumable items would be valued less highly than would their fluent counterparts. Consequently, we expected that participants in the disfluentitems condition would attach a lower value to each of the 10 items, ultimately leading them to believe that the dollar was capable of purchasing more of those goods.

\section{EXPERIMENT 3}

\section{Method}

Participants. A diverse sample of 58 adult participants at a train station in Princeton Junction, New Jersey, and student participants in dining halls at Princeton University volunteered to take part in the experiment.

Design, Materials, and Procedure. Participants completed one of three questionnaires. The familiar-currency questionnaire depicted a standard $\$ 1$ bill and was identical to the familiar-currency questionnaire from Experiment 1. The unfamiliar-currency questionnaire was the same as the familiar-currency questionnaire, except that, in place of the standard $\$ 1$ bill, there was a subtly altered $\$ 1$ bill (see Figure 1): The altered bill depicted George Washington facing left instead of right; the "ONE" seal from the back of the bill was moved to the front left of the bill; the series seal was moved from the front left to the front right of the bill; and the position of the treasurer's signature at the bottom right of the bill and the bill's serial number at the top right of the bill were exchanged. Finally, the disfluent-items questionnaire depicted a standard \$1 bill, but the consumable items were printed in a disfluent 10-point gray, italicized, Arial font (sample), rather than in the standard 12-point black Times New Roman font used in the other conditions (sample). Such font manipulations are a popular method of manipulating the fluency with which participants process printed information (Alter \& Oppenheimer, 2008b). We did not ask participants how familiar the notes were, since the altered bill was novel, but we excluded the responses of 1 participant who questioned its authenticity at the end of the study.

\section{Results and Discussion}

A repeated measures ANOVA demonstrated that the familiarity of the depicted currency and the fluency of the consumable items influenced participants' purchasing power estimates $\left[F(2,18)=23.67, p<.001, \eta_{\mathrm{p}}^{2}=.73\right]$ (see Figure 3). To examine these effects more closely, we conducted three planned pairwise contrasts (controlling for Type I error rates) comparing participants' purchasing estimates across the three conditions. As in Experiments 1 and 2, participants in the familiar-currency condition be- 


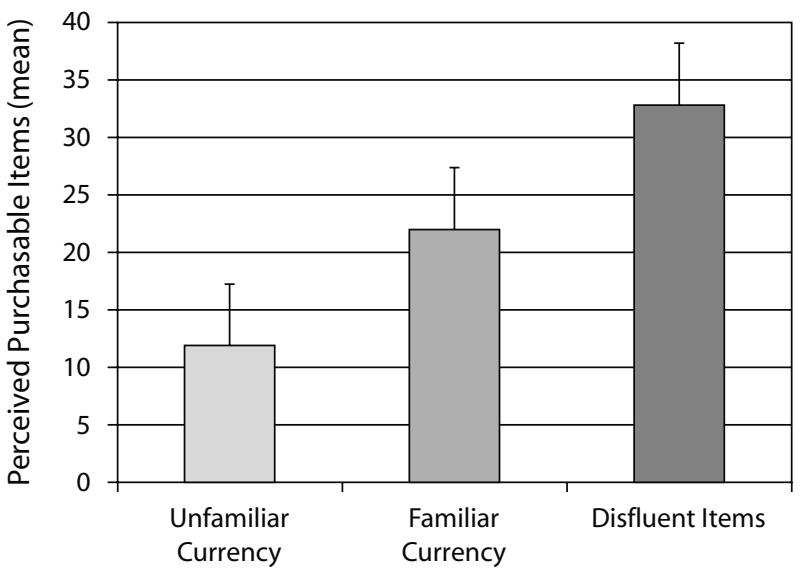

Figure 3. Purchasing power of $\$ 1$ (averaged across 10 consumable items) in Experiment 3. Each mean is significantly different from the others (all $p s<.05)$.

lieved that \$1 had greater purchasing power than did those in the unfamiliar-currency condition across the 10 items $\left[t(9)=2.87, p=.018, \eta_{\mathrm{p}}^{2}=.48\right]$; however, participants in the disfluent-items condition perceived greater purchasing power in the $\$ 1$ bill than did participants in either the familiar-currency $\left[t(9)=4.61, p=.001, \eta_{\mathrm{p}}^{2}=.70\right]$ or the unfamiliar-currency $\left[t(9)=5.33, p<.001, \eta_{\mathrm{p}}^{2}=.76\right]$ condition. ${ }^{3}$

These experiments collectively show that unfamiliar currency instruments and disfluent purchasable goods appear to be less valuable than their familiar and fluent counterparts. Indeed, across the monetary familiarity conditions present in all three experiments (and excluding the disfluent-items condition in Experiment 3), participants believed that they could purchase greater quantities of 28 of the 30 items $(93.33 \%)$ with the familiar forms of currency than with the unfamiliar forms of currency, a significantly greater proportion than might be expected by chance $\left[\chi^{2}(1, N=30)=22.53, p<.001\right]($ see Table 1$)$.

\section{GENERAL DISCUSSION}

Across three experiments, we found that participants perceived greater purchasing power in familiar forms of currency than in their equivalent but less familiar counterparts. This effect held regardless of whether we contrasted a fluent $\$ 1$ bill with a rare coin, with a rare bill, or with a subtly altered version of the same $\$ 1$ bill. The results of Experiments 1 and 2 left open the possibility that participants merely responded to the global experience of disfluency that is associated with unfamiliarity by assigning lower valuation estimates. In Experiment 3, however, we found that participants perceived that the source of unfamiliarity or disfluency was less valuable, whether the source was a currency instrument or a consumable item. This finding suggests that people associate unfamiliarity or disfluency with its specific source, rather than with the judgment context at large. Consistent with existing research (Alter \& Oppenheimer, 2008b), moreover, two different instantiations of fluency-familiarity and visual clarity - appeared to have similar effects on participants' valuation estimates. These convergent results suggest that familiar stimuli seem more valuable at least in part because they are processed more fluently.

\section{Theoretical Implications}

This article builds on a considerable body of work demonstrating that metacognition influences judgment across a broad array of domains (Alter \& Oppenheimer, 2008b). Specifically, we found that the metacognitive experience of disfluency that is associated with processing unfamiliar stimuli led people to assign lower value to currency instruments and consumable goods.

In addition, Experiment 3 presented novel evidence that people attribute familiarity or fluency to its specific source. Rather than generally attenuating participants' valuation judgments, the experience of disfluency diminished the apparent value only of the stimuli that were unfamiliar or difficult to process. Thus, unfamiliar currency instruments seemed less valuable than familiar forms of currency, and consumable goods printed in a difficultto-read font seemed less valuable than the same goods printed in a clear font.

Just as participants in the present research were capable of attributing processing ease to its specific source (currency vs. consumable items), people tend to discount fluency as an informative cue when it does not seem to originate from the relevant judgmental target. Thus, although people generally assume that fluently processed surnames are more common, they discount fluency as an informative cue when the name is shared by a famous person, such as Bush, Gore, or Clinton (Oppenheimer, 2004).

\section{Practical Implications}

This research suggests that national governments should think carefully before amending their country's currency instruments. In fact, the U.S. government recently introduced numerous currency updates, unveiling plans to produce a new series of banknotes covering all denominations from $\$ 5$ to $\$ 100$ in August 2008, shortly after announcing that 38 "Presidential" $\$ 1$ coins would be released between 2007 and 2016. A similar announcement in 1999 preceded the release of 50 "U.S. State" quarters between 1999 and 2008 .

The Treasury's official motivation for these updates seems somewhat frivolous: to "return . . . circulating [currency] to its position as an object of aesthetic beauty" (Presidential \$1 Coin Act, 2005). This article suggests that seemingly innocuous decisions to update currency instruments might diminish the perceived value of the currency, with unintended economic consequences. More generally, these findings show that psychological theory has important implications for economic theory and policymaking.

\section{Conclusion}

Valuation is a task laden with uncertainty, because there is no consistent universal scale against which to measure an item's value. Many items, such as food and water, seem more valuable in some contexts (e.g., following a fast) than in others (e.g., following a feast), and consumable 
items are so diverse (e.g., a goldfish vs. the services of a mechanic) that their values are difficult to compare on a common scale. In response to such uncertainty, our research suggests that people rely on the ubiquitous metacognitive cue of fluency to determine the value of both currency and consumable items. As a simple rule of thumb, people perceive greater value in easily processed goods than in their less easily processed, but otherwise identical, counterparts.

\section{AUTHOR NOTE}

This research was supported by National Science Foundation Grant 051811. We thank Alan Castel, Margaret Gerbasi, Melissa Miller, Priya Raghubir, Rolf Reber, Anuj Shah, Catherine Wolpe, and Jeffrey Zemla for their assistance. Correspondence should be addressed to A. L. Alter, Psychology Department, Princeton University, Princeton, NJ 08544 (e-mail: aalter@princeton.edu).

\section{REFERENCES}

Alter, A. L., \& Oppenheimer, D. M. (2006). Predicting short-term stock fluctuations by using processing fluency. Proceedings of the National Academy of Sciences, 103, 9369-9372.

Alter, A. L., \& Oppenheimer, D. M. (2008a). Effects of fluency on psychological distance and mental construal (or why New York is a large city, but New York is a civilized jungle). Psychological Science, 19, 161-167.

Alter, A. L., \& Oppenheimer, D. M. (2008b). Uniting the tribes of fluency to form a metacognitive nation. Manuscript submitted for publication.

Alter, A. L., Oppenheimer, D. M., Epley, N., \& Eyre, R. N. (2007). Overcoming intuition: Metacognitive difficulty activates analytic reasoning. Journal of Experimental Psychology: General, 136, 569-576.

Birnbaum, M. H., \& Zimmermann, J. M. (1998). Buying and selling prices of investments: Configural weight model of interactions predicts violations of joint independence. Organizational Behavior \& Human Decision Processes, 74, 145-187.

Bureau of Engraving and Printing (2008). Facts about $\$ 1$ notes. Retrieved February 2, 2008, from www.moneyfactory.gov/document .cfm/18/2230.

Cannon, E., \& Cipriani, G. P. (2006). Euro-illusion: A natural experiment. Journal of Money, Credit, \& Banking, 38, 1391-1403.

FAMA, E. F. (1965). The behavior of stock-market prices. Journal of Business, 38, 34-105.

Fang, X., Singh, S., \& Ahluwalia, R. (2007). An examination of different explanations for the mere exposure effect. Journal of Consumer Research, 34, 97-103.

HaNemanN, W. M. (1994). Valuing the environment through contingent valuation. Journal of Economic Perspectives, 8, 19-43.

Mishra, H., Mishra, A., \& Nayakankuppam, D. (2006). Money: A bias for the whole. Journal of Consumer Research, 32, 541-549.

OPPENHEIMER, D. M. (2004). Spontaneous discounting of availability in frequency judgment tasks. Psychological Science, 15, 100-105.

Prelec, D., \& Simester, D. (2001). Always leave home without it: A further investigation of the credit card effect on willingness to pay. Marketing Letters, 12, 5-12.

Presidential \$1 Coin Act of 2005, Pub. L. No. 109-145, 119 Stat. 2664 (2005).

RAGHUBIR, P. (2006). An information processing review of the subjec- tive value of money and prices. Journal of Business Research, 59, 1053-1062.

RaghubiR, P., \& SRIVASTAVA, J. (2002). Effect of face value on product valuation in foreign currencies. Journal of Consumer Research, 29, 335-347.

RaghubiR, P., \& SRivastava, J. (in press). Monopoly money: The effect of payment coupling and form on spending behavior. Journal of Experimental Psychology: Applied.

SLovic, P. (ED.) (2000). The perception of risk. London: Earthscan.

Sunstein, C. R. (2002). Risk and reason: Safety, law, and the environment. New York: Cambridge University Press.

Sunstein, C. R., Hastie, R., Payne, J. W., Schkade, D. A., \& Viscusi, W. K. (2002). Punitive damages: How juries decide. Chicago: University of Chicago Press.

THALER, R. (1980). Toward a positive theory of consumer choice. Journal of Economic Behavior \& Organization, 1, 39-60.

TVERSKY, A., \& Kahneman, D. (1973). Availability: A heuristic for judging frequency and probability. Cognitive Psychology, 5, 207-232.

TVersky, A., \& Kahneman, D. (1974). Judgment under uncertainty: Heuristics and biases. Science, 185, 1124-1131.

Winkielman, P., \& CACioppo, J. T. (2001). Mind at ease puts a smile on the face: Psychophysiological evidence that processing facilitation elicits positive affect. Journal of Personality \& Social Psychology, 81, $989-1000$

ZaJonc, R. B. (1968). Attitudinal effects of mere exposure. Journal of Personality \& Social Psychology, 9, 1-27.

\section{NOTES}

1. We also sought to eliminate the possibility that some participants in the unfamiliar-currency condition offered lower estimates because they did not believe that the Susan B. Anthony coin was legal tender. This explanation seemed unlikely, since (1) the questionnaire asked participants to estimate the purchasing power of $\$ 1$, generally, and merely provided the image of the coin as a reference; (2) none of the participants reported purchasing power estimates of zero for any of the 10 items, eliminating the possibility that they believed that the coin was fabricated; (3) when the experimenter collected the completed questionnaire and explained the purpose of the study, none of the participants questioned the coin's authenticity; and (4) even after we had eliminated the 4 participants who were completely unfamiliar with the coin, the results remained significant. Similar analyses in Experiments 2 and 3 allayed the same concerns.

2. This discrepancy between our results and Mishra et al.'s (2006) is not surprising, given that their whole-part effect relies on the difficulty of summing values of multiple bills. Summing two $\$ 1$ bills after being told their total value (as participants did in our study) is not comparable to summing five bills of various denominations to an unknown value (as participants did in their study). The disfluency engendered by summing in our study was trivial, and consequently it appears to have been overshadowed by familiarity effects.

3. As in Experiments 1 and 2, we examined the data for evidence that participants in the unfamiliar-currency condition doubted the altered bill's authenticity. Except for the 1 participant whose data were excluded when he recognized that the altered bill was fabricated, none of the participants provided purchasing power estimates of zero for any of the 10 items. Thus, the effects were unlikely to have been driven by participants who believed that the altered currency was fabricated and therefore valueless.

(Manuscript received February 12, 2008; revision accepted for publication March 28, 2008.) 